\title{
CHROMOSOME POLYPLOIDIZATION IN HUMAN LEUKOCYTES INDUCED BY RADIATION
}

\author{
Carlos E. Nasjleti and Herbert H. Spencer \\ The Veterans Administration Hospital and The University of Michigan, \\ Ann Arbor, Mich.
}

\section{INTRODUCTION}

A great quantity of literature has accumulated on the effects of radiation and radiomimetic agents upon cells. Much of this work has been performed on mammalian cells both in vivo and in tissue cultures. Some of these damaging effects can be seen in dividing cells.

After the development of a technique for tissue cuiture of human peripheral blood, we were able to demonstrate abnormal patterns and chromosomal polyploidy in cultures from patients who had been treated with A-8103 (a piperazine derivative with antitumor activity), ${ }^{1}$ nitrogen mustard, 6-mercaptopurine, and A-649 (another antitumor agent). ${ }^{2}$ During treatment and for some time after treatment in these patients, structural changes could be seen in the chromosomes as either chromatid or chromosome deletions and chromosomal breakage. Abnormally shaped chromosomes were also seen, particularly ring forms and dicentrics. Although aneuploidy was observed, the major numerical variation consisted of metaphases showing polyploidy with random distribution of chromosomes and diplochromosomes. When normal human leukocytes were tested in vitro with the chemotherapeutic agents already mentioned, as well as with streptonigrin and cyclophosphamide, ${ }^{3}$ similar results were obtained. From these studies we postulated that two different types of damage were induced in the cells by the chemicals. One type of damage is apparent in the hereditary material, and it can be characterized by the structural chromosomal changes. The second type of damage is interpreted as damage to the mitotic apparatus of the cells, as evidenced by the induction of polyploidy. Simultaneously, initial studies from patients treated with $x$-rays and cobalt- 60 demonstrated that the same type of chromosomal anomalies were present in their peripheral leukocytes as those induced with chemotherapeutic agents. Generally, these were structural variations and chromosome polyploidization. Certainly, chromosomal changes have been described in association with $\mathrm{X}$-radiation ${ }^{4,5}$ and ${ }^{131} \mathrm{I}$ therapy ${ }^{6,7}$ and, rarely, following diagnostic $\mathrm{X}$-radiation. However, in most of these reports, the occurrence of polyploidy was overlooked, and when polyploidy was mentioned, it was not characterized.

Since both structural damage as well as polyploidy lead to genetic transformation or to somatic cell death, we thought it of paramount interest to determine whether or not induction of chromosomal polyploidy by radiation was a constant feature in human somatic cells. Such effects may have a bearing on both the induction as well as the treatment of cancer.

For the present study, we determined not only polyploidy, but also the amount of aneuploidy, chromosomal breakage, ring forms, translocations, dicentrics, and tricentrics as well as other rearrangements appearing in patients exposed to radiation therapy. In addition, normal human leukocytes were exposed to $\mathrm{x}$-rays in cultures, and information of induced damage was obtained. 


\section{Materials AND Methods}

\section{In Vivo Studies}

Samples of blood for culture were taken from 12 patients who had received radiation therapy: Five treated with oral radioactive iodine $\left({ }^{131} \mathrm{I}\right)$, three treated with $\mathrm{x}$-rays, and four with $\gamma$-rays from a cobalt- 60 source. The dose of radiation was from 800-6,085 r given over 8-45 days. Most of these patients were suffering from cancer but four were treated for hyperthyroidism. ${ }^{9}$ These men were from 33-74 years of age. The blood samples $(10-15 \mathrm{ml})$ were taken before, during, and sometimes after irradiation. Blood from normal controls were cultured along with that from treated patients. The culture method used was slightly modified from the original technique of Moorhead et al. ${ }^{8}$ described previously. ${ }^{9}$ Briefly, heparinized blood, after drawing, was left in a vacuum tube at room temperature $\left(27^{\circ} \mathrm{C}\right)$ for one hour to let erythrocytes sediment. Then $2 \mathrm{ml}$ of leukocyte ladden plasma were added to $8 \mathrm{ml}$ of culture medium 199 (Difco, Co.) containing penicillin and streptomycin, so that the seeding had a concentration of approximately $1 \times 10^{5}$ cells $/ \mathrm{ml}$. Final volume per culture was $10 \mathrm{ml}$ and the ratio of supernate to medium was $1: 4$. To each bottle, $0.5 \mathrm{ml}$ of Phytohemagglutinin $\mathrm{M}$ (Difco, Co.) was added. Culture bottles were incubated at $37^{\circ} \mathrm{C}$ in an atmosphere of 5 percent carbon dioxide and 95 percent air. Bottles were shaken twice daily during incubation. Between 65-67 hours after culture initiation, $0.1 \mathrm{ml}$ of Colcemid ${ }^{\circledR}$ (Ciba Lab.) in a concentration of $10^{-6} \mathrm{M}$ was added. At 72 hours these cells were hypotonically treated with distilled water and fixed with methanol-glacial acetic acid (3:1) mixture. Chromosomal spreading was accomplished by fanning and flaming. For staining, a solution of 2 percent aceto-orcein was used. Plates were scanned for mitotic metaphases under the microscope and metaphases that appeared intact were photographed. The transparencies $(2 \times 2$ inches $)$ obtained were projected on a screen for study. When possible, a minimum of 100 mitosis per culture was analyzed for chromosome number as well as for structural aberrations. Final analysis and karyotypes were prepared following the Denver nomenclature. ${ }^{10}$

\section{In Vitro Studies}

For these series the same technique was used except that blood from healthy individuals (one woman and four men) was used, half of the cultures were irradiated, and the total incubation time was 100 hours.

After obtaining blood from the five normal donors, ten cultures were set up and incubated. After 48 hours of incubation, the ten aliquots were taken from the incubator. To five aliquots a $200 \mathrm{r}$ dose of $\mathrm{x}$-radiation was given, using a conventional Westinghouse therapy machine operated at $250 \mathrm{KVP}, 15 \mathrm{MA}$ with $1 / 2 \mathrm{~mm} \mathrm{Cu}$ and $1 \mathrm{~mm} \mathrm{Al} \mathrm{filters.} \mathrm{For} \mathrm{the} \mathrm{radiation} \mathrm{procedure,} \mathrm{each} \mathrm{bottle} \mathrm{was}$ placed on a 2-inch board of masonite and received a dose rate of $30.2 \mathrm{r} / \mathrm{min}$ for six minutes and 37 seconds. The remaining five aliquots were handled identically but did not receive actual irradiation. Following both the true and sham radiation, all ten aliquots were returned to the incubator for an additional 48 hours, after which Colcemid was added. After 100 hours, cells were taken from the incubator and thereafter handled as in the in vivo work.

\section{RESULTS}

Cytogenetic studies from normal controls and from patients before radiation therapy were similar and showed a small percentage of breaks and aneuploidy as shown in TABLE 1. Most cells were characterized by a normal chromosomal complement (FIGURE 1). 


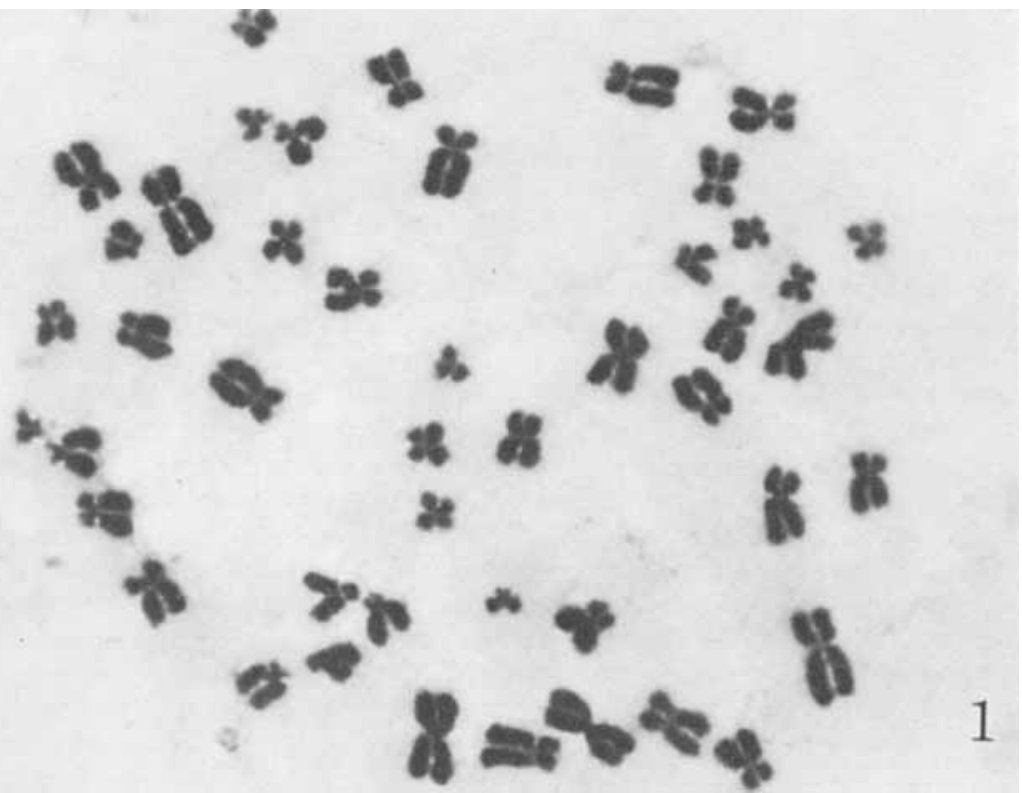

Figure 1. Normal female diploid metaphase obtained in a control culture. Aceto-orcein stain. $\times 1,400$; orig. mag. $\times 2,000$.

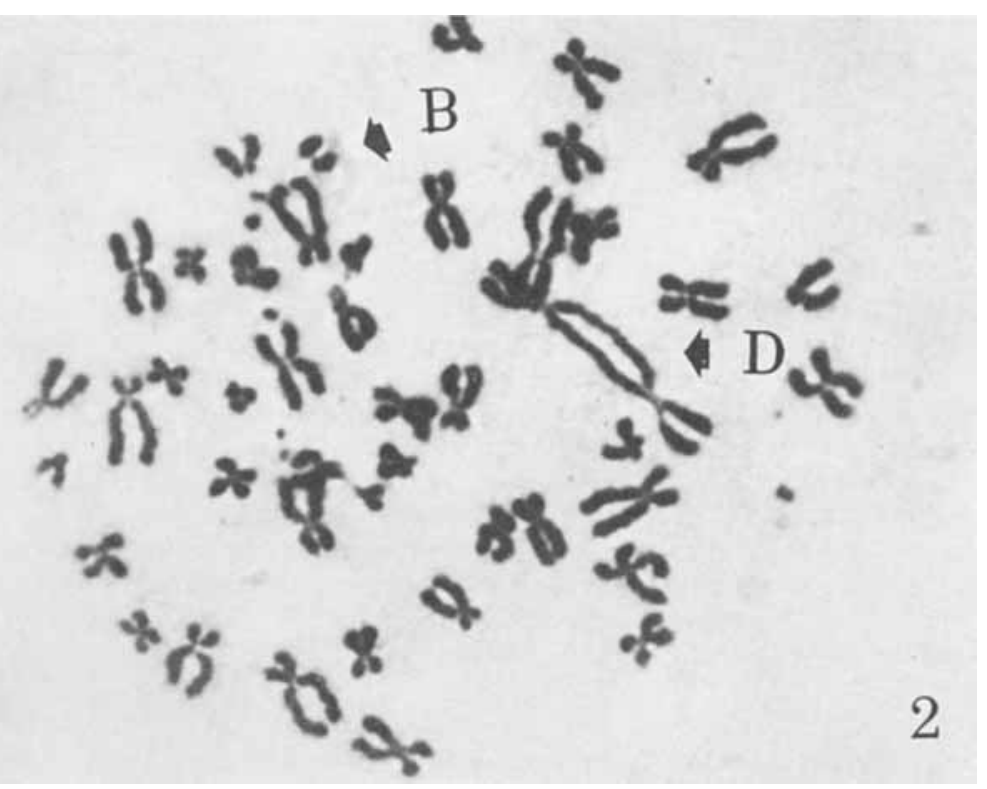

FIGURE 2. Hypoploid metaphase with chromosomal breakage $(B)$ and dicentric chromosome (D) in a 72-hour culture of peripheral leukocytes from a patient treated with ${ }^{131}$ I. Acetoorcein stain. $\times 1,400$; orig. mag. $\times 2,000$. 
When chromosomal analyses were obtained one week following ${ }^{131}$ I therapy, an increase in structural chromosome aberrations was evident. For the most part these aberrations consisted of unstable chromosomal type damage, such as acentric fragments, rings, and dicentrics. FIGURE 2 shows a hypoploid cell demonstrating this type of damage. In addition, an increase in polyploid metaphases was

TABLE 1

Chromosome Patterns before Radiation Therapy

\begin{tabular}{lcccc}
\hline & $\begin{array}{c}\text { Total } \\
\text { Cells Counted }\end{array}$ & $\begin{array}{c}\text { Percent Celis } \\
\text { with Structural } \\
\text { Changes* }\end{array}$ & $\begin{array}{c}\text { Aneuploidyt } \\
\text { Percent }\end{array}$ & $\begin{array}{c}\text { Tetraploidy } \\
\text { Percent }\end{array}$ \\
\hline Normal controls & 1200 & 4 & 5 & 0.5 \\
Patients before treatment & 1200 & 3 & 5 & 0.5 \\
\hline
\end{tabular}

* Only chromosome breaks were seen.

$\dagger$ Aneuploid cells having one or two chromosomes missing or in excess.

TABLE 2

Chromosome Count Distribution after One Treatment with ${ }^{231}{ }^{\text {* }}$

\begin{tabular}{|c|c|c|c|c|}
\hline Diagnosis & Dose $(\mathrm{mC})$ & $\begin{array}{c}\text { Diploidy } \\
\text { Percent }\end{array}$ & $\begin{array}{c}\text { Aneuploidy } \\
\text { Percent }\end{array}$ & $\begin{array}{l}\text { Tetraploidy } \\
\text { Percent }\end{array}$ \\
\hline $\begin{array}{l}\text { Thyrotoxicosis } \dagger \\
\text { (four patients) }\end{array}$ & $5.5-9$ & 86 & 5 & $9(4) \ddagger$ \\
\hline $\begin{array}{c}\text { Thyroid cancer } \dagger \\
\text { (one patient) }\end{array}$ & 150 & 83 & 5 & $12(3) \ddagger$ \\
\hline
\end{tabular}

* Cultures established within one week after therapy.

$\dagger 100$ metaphases were analyzed from each patient.

$\ddagger$ Numbers in parenthesis indicate number of tetraploid cells that showed endoreduplication.

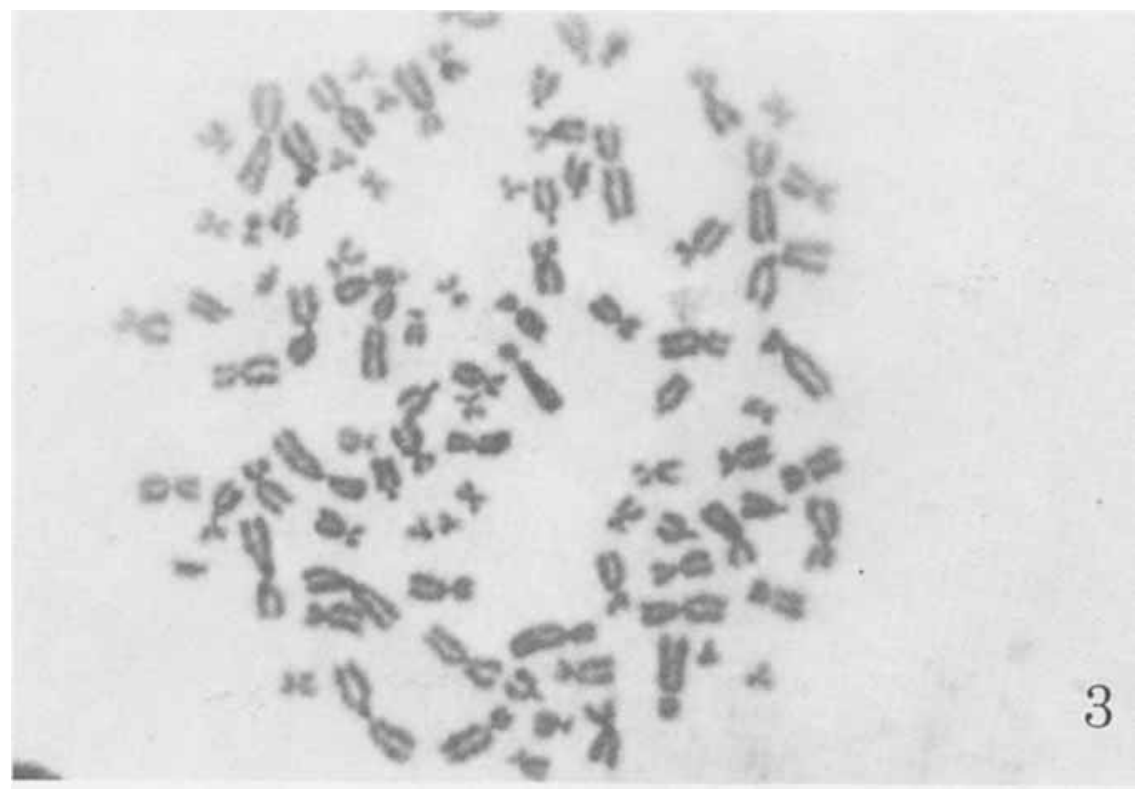

FIGURE 3. Tetraploid metaphase with random chromosome distribution in a 72-hour culture of peripheral leukocytes from a patient treated with ${ }^{131}$. Aceto-orcein stain. $\times 1,120$; orig. mag. $\times 1,600$. 


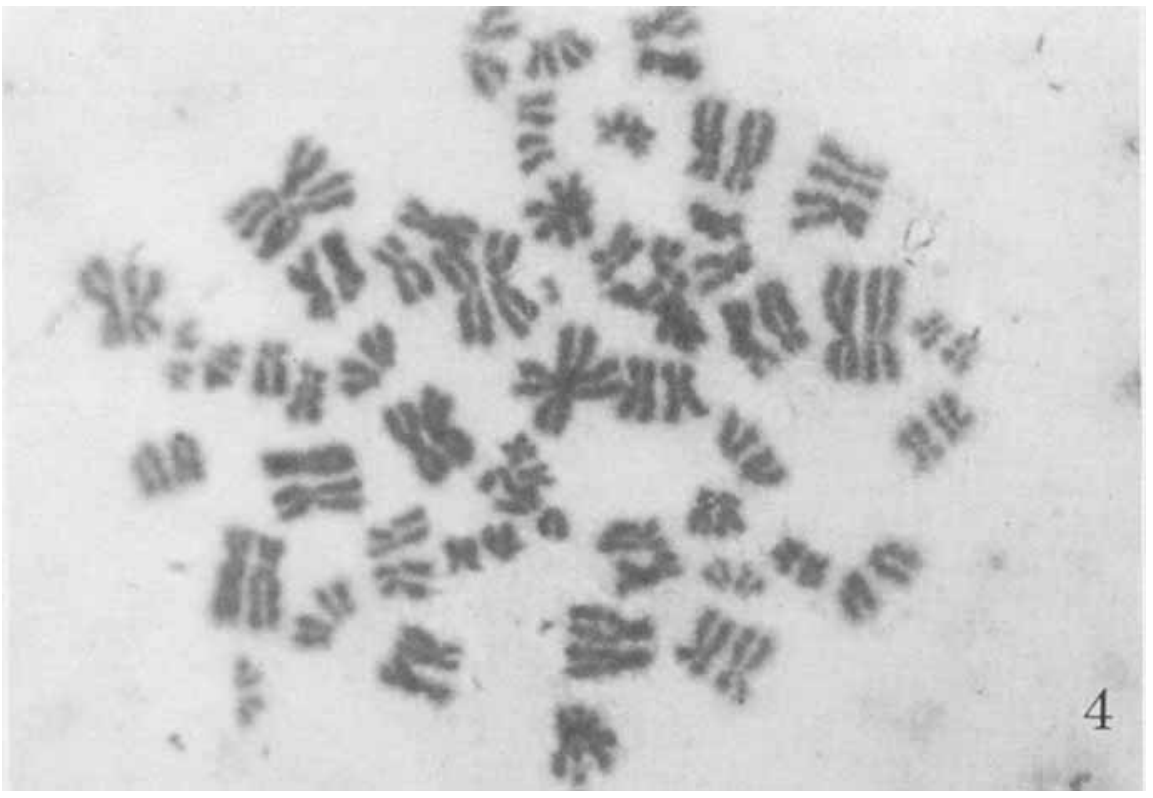

FIGURE 4. Tetraploid endoreduplicated metaphase with typical diplochromosomes in a 72-hour culture of peripheral leukocytes from a patient treated with ${ }^{131}$ I. Aceto-orcein stain. $\times 1,120$; orig. mag. $\times 1,600$.

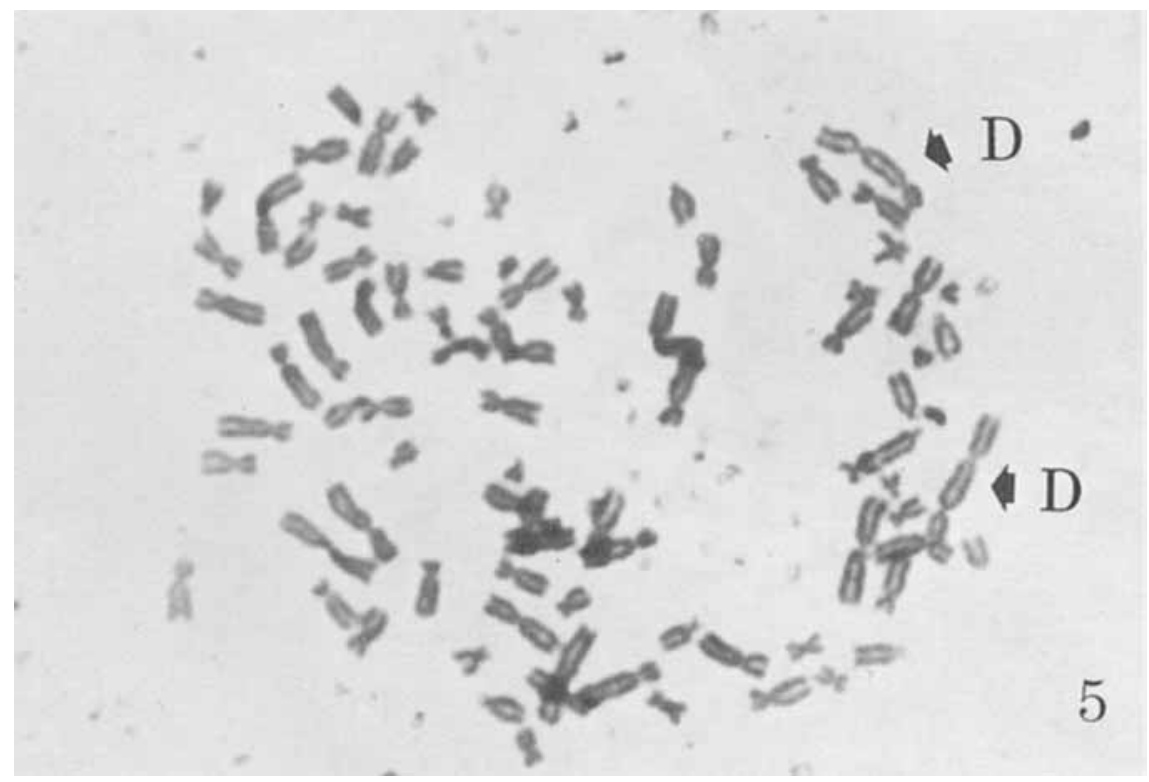

Figure 5. Heteroploid metaphase with dicentric chromosomes (D) in a 72-hour culture of peripheral leukocytes from a patient treated with ${ }^{131}$. Aceto-orcein stain. $\times 1,120$; orig. mag. $\times 1,600$. 
noted. Tetraploid mitoses constituted the major part of the polyploidy population. However, octoploids and a few cells at the 16-ploidy level were also observed from these patients. Polyploidy was seen with chromosomes distributed at random (FIGURE 3) and in diplochromosomes (FIGURE 4). Furthermore, it was noted that many of the structural aberrations seen in diploids were also seen in tetraploid cells (FIGURE 5).

The one patient, who received a large dose of radioiodine for thyroid carcinoma, did not show any more damage than those patients receiving smaller doses. It seems unlikely that the amount of structural or numerical chromosomal variation will provide an accurate method of biological radiation dosimetry in man. One patient had received radioiodine therapy nine months before our study and showed no chromosome abnormalities in baseline culture. These data are presented in TABLES 2 and 3.

Analyzing 2,200 cells from 22 cultures in patients receiving external radiation (including $x$-ray and cobalt-60) the prompt appearance of numerical changes and structural abnormalities were documented (FIGURE 6). Approximately twothirds of the nonmodal metaphases were polyploid and one-third were aneuploid. The patients developed polyploidy that persisted throughout the course of therapy. The structural abnormalities noted were similar to those which have been de-

TABLE 3

Chromosome Structural Aberrations and Total Damage AFTER ONE TREATMENT WITH ${ }^{131} I^{*}$

\begin{tabular}{|c|c|c|c|c|}
\hline Diagnosis & $\begin{array}{l}\text { Acentric } \\
\text { Fragments } \\
\text { Percent }\end{array}$ & $\begin{array}{l}\text { Dicentrics } \\
\text { Percent }\end{array}$ & $\begin{array}{l}\text { Translocations } \\
\text { and Other } \\
\text { Aberrations } \\
\text { Percent }\end{array}$ & $\begin{array}{c}\text { Total } \\
\text { Damage } \\
\text { Percent }\end{array}$ \\
\hline $\begin{array}{l}\text { Thyrotoxicosis } \dagger \\
\text { (four patients) }\end{array}$ & $10(6) \ddagger$ & $9(7)$ & 1 & $20(13)$ \\
\hline $\begin{array}{l}\text { Thyroid cancert } \\
\text { (one patient) }\end{array}$ & $13(10)$ & $12(10)$ & 1 & $26(20)$ \\
\hline
\end{tabular}

* Cultures established one week after therapy .

+100 metaphases were analyzed from each patient.

$\mp$ Numbers in parenthesis indicate amount of damage found in tetraploid metaphases out of the total number found.

TABLE 4

Tetraploid Cells Including Endoreduplication Analyzed for Dicentrics AND OTHER STRUCTURAL AbERRations

\begin{tabular}{|c|c|c|c|}
\hline Therapy & $\begin{array}{c}\text { Number of Cells } \\
\text { Analyzed }\end{array}$ & $\begin{array}{l}\text { Number of Cells } \\
\text { with Dicentrics }\end{array}$ & Percent \\
\hline \multirow[t]{2}{*}{ 131I } & $\begin{array}{l}R-25 \\
+E-25 \\
\end{array}$ & $\begin{array}{l}{ }^{*} \mathrm{R}-17 \\
+\mathrm{E}-19\end{array}$ & \multirow[t]{2}{*}{72} \\
\hline & 50 & 36 & \\
\hline \multirow[t]{2}{*}{$X$-ray } & $\begin{array}{l}\mathbf{R}-25 \\
E-25\end{array}$ & $\begin{array}{l}R-17 \\
E-20\end{array}$ & \multirow[t]{2}{*}{74} \\
\hline & 50 & 37 & \\
\hline \multirow[t]{2}{*}{ Cobalt -60} & $\begin{array}{l}\mathbf{R}-25 \\
\mathbf{E}-25\end{array}$ & $\begin{array}{l}\mathbf{R}-18 \\
E-18\end{array}$ & \multirow[t]{2}{*}{72} \\
\hline & 50 & -36 & \\
\hline Total & $150 \div$ & 109 & 73 \\
\hline
\end{tabular}

\footnotetext{
- $\mathrm{R}=$ Tetraploid cells with random distribution of chromosomes.

$\dagger \mathbf{E}=$ Tetraploid endoreduplication.

$\ddagger=$ In these tetraploid cells only 44 percent showed acentric fragments.
} 
scribed many times, with the most frequent abnormalities being the formation of dicentric chromosomes and acentric fragments. It was again noted that the structural aberrations were frequently present in the tetraploid cell.

In our material, when fifty tetraploid cells were selected from each group of patients (treated with ${ }^{131} \mathrm{I}, \mathrm{x}$-ray, and cobalt-60), and these 150 cells analyzed for chromosome structural damage, it was noted that 73 percent of these cells contained dicentrics and 44 percent contained chromosomal fragments (TABLE 4).

In addition, fragmented cells were common in these preparations in which the fragmented chromosome segments underwent pycnotic condensation in the cytoplasm. At other times, cells showed various degrees of superfragmentation of the chromosomes with hyperchromatic micronuclei adjacent to it (FIGURE 7). Similar results were obtained by Koller ${ }^{11}$ working with alkylating agents on cells of the Walker rat carcinoma 256.

When human leukocyte cultures were irradiated with $200 \mathrm{r}$ and control cultures were not irradiated, marked differences were seen. A high degree of polyploidy

TABLE 5

Summary of Chromosomal Aberrations Seen Following in Vitro X-Radiation with $200 \mathrm{R}$

\begin{tabular}{lcccc} 
& $\begin{array}{c}\text { Cells } \\
\text { Counted }\end{array}$ & $\begin{array}{c}\text { Structural } \\
\text { Changes* } \\
\text { Percent }\end{array}$ & $\begin{array}{c}\text { Aneuploidy } \\
\text { Percent }\end{array}$ & $\begin{array}{c}\text { Tetraploidy } \\
\text { Percent }\end{array}$ \\
\hline Control & 500 & 3.8 & 5.4 & 0 \\
Irradiated cultures & 500 & 52 & 3.2 & $12.2 \dagger$ \\
\hline
\end{tabular}

* Fragments, dicentrics, and translocations.

+ Approximately half of the tetraploid cells showed endoreduplication.

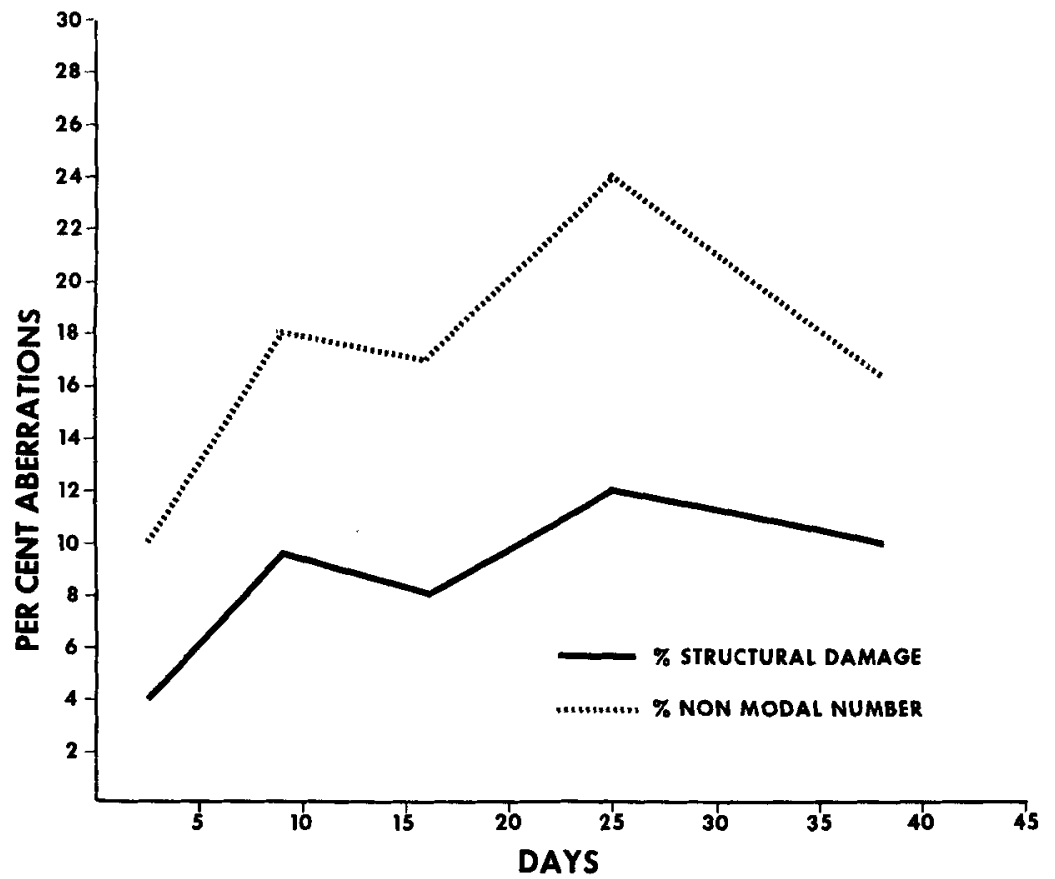

FIGURE 6. Relationship of damage to time during treatment in patients receiving external radiation. 


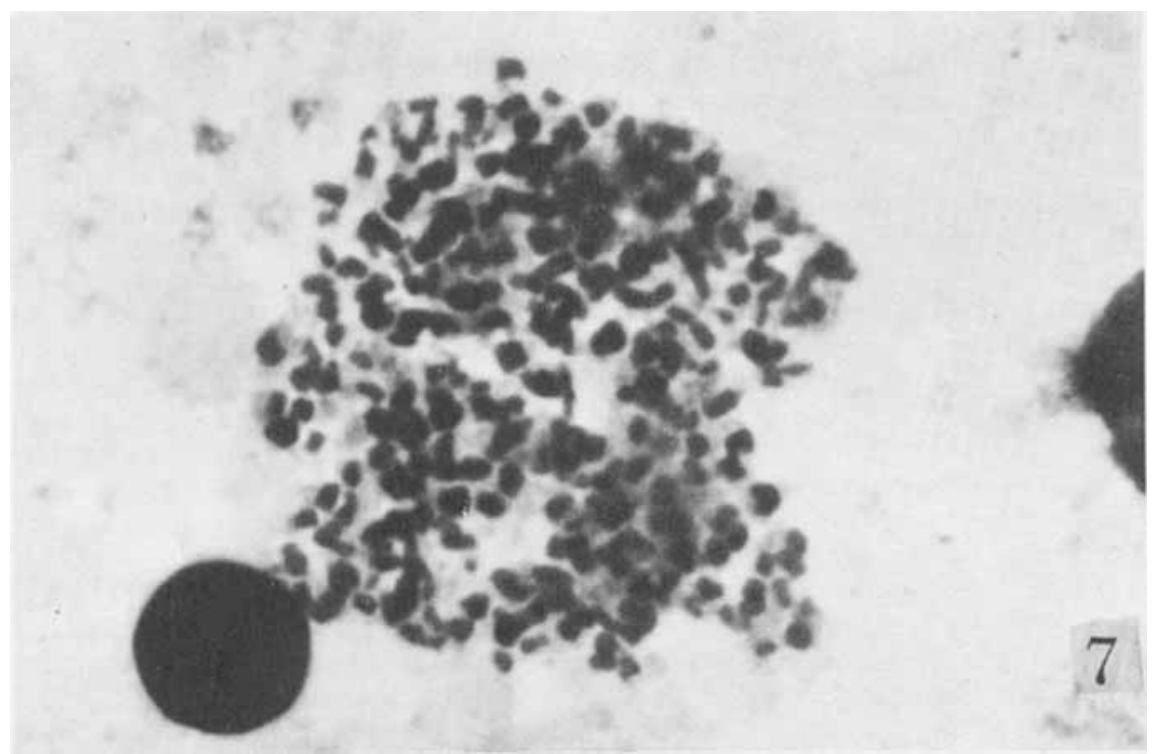

Figure 7. Damaged cell showing superfragmentation of chromosomes in a 72-hour culture of peripheral leukocytes from a patient treated with $x$-rays. Aceto-orcein stain. $\times 1,400$; orig. mag. $\times 2,000$.

and endoreduplication was noted as well as a high percentage of structural abnormalities reaching over 50 percent in some instances (TABLE 5).

\section{Discussion}

It has long been known that radiation from $\mathrm{x}$-rays and radioisotopes are capable of inducing mutations, as well as mitotic and chromosomal anomalies in human leukocytes. ${ }^{12}$ However, relatively few of these studies characterized the chromosomal polyploidization, and thus failed to estimate the total extent of cytogenetic damage.

We have recently studied polyploidy induced by $\mathrm{x}$-rays in human leukocyte cultures. ${ }^{9}$ We observed polyploidy with random distribution of chromosomes and diplochromosomes. Levan and Hauschka ${ }^{13}$ have considered the configuration of diplochromosomes at metaphase to be the result of endoreduplication. The fact that an endoreduplicated cell with diplochromosomes is a form of polyploidy was demonstrated by Bell, ${ }^{14}$ who used two-wavelength microspectrophotometry to show that tetraploid endoreduplicated cells in an $x$-irradiated culture of human leukocytes contained about twice as much DNA as diploid cells from the same culture. An earlier review by Geitler ${ }^{15}$ showed that endoreduplication has been described in different plant and animal tissues. Diplochromosomes have also been reported in human tumor cells. ${ }^{16-19}$

This investigation was undertaken to provide more needed information on polyploidy induction from ionizing radiation in vivo. Unfortunately, many of our patients died in the course of the study leaving us with only a small amount of material for evaluation. Furthermore, an unusually high percentage of cultures established from these patients during treatment failed to grow. Previous experience with patients treated with chemotherapeutic agents for cancer did not pro- 
duce such a high number of failures. Perhaps, this failure rate could be related to an additional cellular damage induced by radiation in these cases.

It appears that polyploidy is an important change following irradiation, and that this aberration seems to be a fairly constant feature. The time interval, however, during which this abnormality persists cannot be ascertained from our material, and further studies will be needed to settle this question. However, it was noted that structural chromosomal changes and polyploidy persisted during radiation therapy in these patients. In several patients, the cells that contained chromosome abnormalities seemed to lose their proliferative capacity. This was evident from the observation of cytogenetic studies in three patients (two treated for cancer and one for hyperthyroidism). performed three to five months after irradiation, when the large majority of their leukocyte metaphases were characterized by a normal chromosomal complement without evidence of damage. Another patient, who received treatment 11 and nine months prior to our baseline evaluation, showed no evidence of damage before the third therapy with ${ }^{131}$ I. However, other studies have shown that damage may persist for many years after radiation exposure. Particularly pertinent is the report of Bender and Gooch, ${ }^{20}$ who observed chromosomal abnormalities 29 months after radiation in leukocyte cultures of a number of subjects who had been accidentally exposed to mixed gamma and fission neutron irradiation. Calculated absorbed doses received by these individuals varied from 22.8-365 rads. Buckton et al. ${ }^{4}$ reported that abnormalities persisted for as long as 18 years after $\mathrm{x}$-irradiation in patients treated for ankylosing spondylitis. Recently, Nofal and Beierwaltes ${ }^{6}$ noted a statistically significant increased incidence of chromosomal aberrations in count and morphology both acutely and to a lesser extent chronically after radioiodine therapy for hyperthyroidism. These abnormalities were detected as early as one-half hour after the therapy dose, and were found in certain patients 14 years after treatment. These observations on the persistence of chromosomal damage after radiation therapy, lead us to a related consideration that would appear to be of much interest to the present audience.

It is now generally accepted that the metaphases we are analyzing are from transformed lymphocytes in the cultures, ${ }^{21}$ but we are uncertain as yet about the life-span of these circulating cells. The persistence of chromosomal aberrations in peripheral lymphocytes for one year or longer after radiation, suggests a possibility that the life-span of lymphocytes may be considerable longer than twoor three-hundred days, as has been recently suggested by Yoffey. ${ }^{22}$ However, in our material we observed octoploid and sometimes 16-ploid metaphases from patients during radiation. This seems to indicate that a certain number of lymphocytes in the circulating blood are actively dividing. Present evidence indicates that circulating lymphocytes are in $\mathrm{G}_{0}$ stage and that in short term or 72 hour cultures, lymphocytes undergo a single division as has been demonstrated by MacKinney et al. ${ }^{23}$ Those octoploid and 16-ploid cells clearly must have undergone more than one division in the donor's blood, otherwise it would be difficult to explain the finding of cells with such high polyploidy. In addition, although a high degree of polyploidy is good evidence to suggest that these dividing lymphocytes exist, the information gained from radiation-induced tetraploidy from these patients also provides evidence of this. Moreover, in our irradiated cultures using ${ }^{3} \mathbf{H}$-thymidine we have seen tetraploids originate from two successive chromosome duplications. The cycle leading to tetraploid cells has approximately the same duration as two cycles of a diploid cell. Certainly this is true for tetraploid metaphases bearing diplochromosomes as well.

Another of our observations is of particular interest. When 150 tetraploid 
mitoses (75 showing random distribution of chromosomes and 75 showing diplochromosomes) were studied from our patients and were analyzed for the incidence of structural chromosomal aberrations, the following were observed: (1) The only damage seen in these cells were acentric fragments and dicentric chromosomes (three cells showed tricentrics). Ring forms, triradials, quadriradials, or rearrangements were not observed. (2) Dicentrics in numbers of two, four, and sometimes six were detected in 73 percent of tetraploid cells analyzed. (3) Chromosomal breakage was observed only in cells with dicentrics, whereas fragments alone were not seen in these tetraploid cells.

We think that there may be an important point here. Since 27 percent of the cells showed no dicentrics or other noticeable damage, one possibility is that polyploidy could be an independent consequence of the radiation injury to the mitotic apparatus. The possibility that dicentrics and polyploid cells are induced by radiation in different ways is understandable because many target areas may be involved simultaneously. One always sees an increase in the number of acentric fragments, dicentrics, ring forms, and many types of translocations and rearrangements, as well as polyploids in irradiated material. It is evident from this analysis that polyploidy may be related to damage to the mitotic mechanism, and that it may occur without apparent additional chromosomal damage.

On the other hand, we found 73 percent of polyploid cells showing dicentrics, usually accompanied by fragments but no other chromosome-type damage. One also can understand the appearance of dicentrics and fragments together, since these two events are related, and breakage is necessary for dicentrics to be formed. But why is there so high a number of dicentrics and no other type of unstable chromosome anomalies in polyploid cells? Are these two aberrations related to one another? Could dicentrics induce polyploidy independently of the polyploidy induced by radiation alone? This is a possibility that is suggested by our data, although we have no evidence or information as to how this kinetic event may occur. However, it is possible that dicentrics may become a permanent bridge interfering with cleavage, thus giving rise to giant cells or polypolar figures. In this regard, Muller ${ }^{24}$ demonstrated that this process appears to be the principal cause of death in early fruit fly (Drosophila melanogaster) zygotes derived from irradiated spermatozoa. The association of this polyploidy and dicentric chromosomes is interesting. However, it is evident that further work exploring this hypothesis will have to be done to gain more definite information concerning the basis for this phenomenon.

\section{SUMMARY}

1. In our patients following radiation therapy, induction of polyploidy was a prominent feature in addition to the usual chromosomal type abnormalities.

2. In most of our patients we were unable to continue long-term investigation following radiation therapy, but in four patients, studied three to nine months following therapy, no increase in chromosomal aberrations were seen.

3. Seventy three percent of 150 tetraploid cells selected following radiation therapy showed dicentric chromosomes and 44 percent contained acentric fragments. No fragments were seen in tetraploid cells unless a dicentric chromosome was present.

4. Similar chromosomal changes were seen following irradiation to human leukocyte cultures.

\section{ACKNOWLEDGMENTS}

We are grateful to Dr. Claire J. Shellabarger, Chief, Kresge Radioisotope Laboratory, University of Michigan Medical Center, and Dr. Robert Rapp, Chief, Radiology Department, Veterans Administration Hospital, for making available 
the facilities used and for advice in some phases of this work. The technical assistance of Mrs. Jean Simons, Mrs. Virginia Hartog, and Mr. Richard Shaw is acknowledged. We are indebted to Mr. Robert McKnight and Mr. Stanley Nance for excellent photographic work, and to Mrs. Doris Watkins for aid with the manuscript.

\section{REFERENCES}

1. Nasjleti, C. E., J. M. Walden \& H. H. Spencer. 1965. Polyploidy and endoreduplication induced in vivo and in vitro in human leukocytes with n, n'-bis-(3-bromopropionyl) piperazine (A-8103). Cancer Res. 25 (3): 275-285.

2. NASIlETI, C. E. \& H. H. SPENCER. 1966. Chromosome damage and polyploidization induced in human peripheral leukocytes in vivo and in vitro with: nitrogen mustard, 6-mercaptopurine, and A-649. Cancer Res. 26(1): 2437-2443.

3. Nasjleti, C. E. \& H. H. Spencer. 1967. Chromosome polyploidization in human leukocyte cultures treated with streptonigrin and cyclophosphamide. Cancer 20(1): 31-35.

4. Buckton, K. E., P. A. Jacobs, W. M. Court-Brown \& R. Doll. 1962. A study of the chromosome damage persisting after $\mathrm{x}$-ray therapy for ankylosing spondylitis. Lancet ii: $676-682$.

5. Warren, S. \& L. Meisner. 1965. Chromosomal changes in leukocytes of patients receiving irradiation therapy. J.A.M.A. 193(5) : 351-358.

6. Nofal, M. M. \& W. H. Beierwaltes. 1964. Persistent chromosomal aberrations following radioiodine therapy. J. Nucl. Med. 5 : 840-850.

7. Boyd, E., W. Watson-Buchanan \& B. Lennox. 1961. Damage to chromosomes by therapeutic doses of radio-iodine therapy. Lancet i: $977-978$.

8. Moorhead, P. S., P. C. Nowell, W. J. Mellman, D. M. Battips \& D. A. Hungerford. 1960. Chromosome preparations of leukocytes cultured from human peripheral blood. Expt. Cell Res. 20: 613-616.

9. Nasjleti, C. E., J. M. Walden \& H. H. Spencer. 1966. Polyploidization and aberration of human chromosomes induced in vitro and in vivo with ionizing radations. J. Nucl. Med. 7: 157-176.

10. Human Chromosome Study Group. 1960. A proposed standard system of nomenclature of human mitotic chromosomes. J. Heredity 51: 213-221.

11. Koller, P. C. 1958. Comparative effects of alkylating agents on cellular morphology. Ann. N. Y. Acad. Sci. 68: 783-801.

12. Wald, N., G. E. Thoma, JR. \& G. Broun, JR. 1962. Hematologic manifestations of radiation exposure in man. In Progress in Hematology. L. M. Tocantins, Ed. Vol. 3. : 1. Grune \& Stratton. New York, N. Y.

13. Levan, A. \& T. S. HauschKa. 1953. Endomitotic replication mechanisms in ascites tumors of the mouse. J. Nat. Cancer Inst. 14: 1-43.

14. BeLL, A. G. 1964. Diploid and endoreduplicated cells: measurements of DNA. Science 143: $139-140$.

15. Geitler, L. 1953. Endomitose und endomitotische Polyploidisierung. Protoplasmatologia $V l / C$. Spring. Vienna, Austria.

16. Levan, A. 1956. Chromosome studies on some human tumors and tissues of normal origin, grown in vivo and in vitro at the Sloan-Kettering Institute. Cancer 9: 648-663.

17. Ising, U. \& A. LeVan. 1957. The chromosomes of two highly malignant human tumours. Acta Path. Microbiol. Scand. 40: 13-24.

18. SaSAKI, M., T. Fukuschima \& S. Makino. 1962. Some aspects of the chromosome constitution of hydatidiform moles and normal chorionic villi. Gann 53: 101-106.

19. Hsu, T. C. \& P. S. Moorhead. 1956. Chromosome anomalies in human neoplasms with special reference to the mechanisms of polyploidization and aneuploidization in the HeLa strain. Ann. N. Y. Acad. Sci. 63: 1083-1095.

20. Bender, M. A. \& P. C. Gooch. 1962. Persistent chromosomes aberrations in irradiated human subjects. Radiat. Res. 16: 44-53.

21. Robrins, J. H. 1964. Tissue culture studies of the human lymphocyte. Science 146: $1648-1654$

22. YofFey, J. M. 1964. Further problems of lymphocyte production. Ann. N. Y. Acad. Sci. 113: $867-886$.

23. MacKinney, A. A., JR., F. Stohlman, Jr. \& G. Brecher. 1962. Kinetics of cell proliferation in cultures of human peripheral blood. Blood 19: 349-358.

24. Muller, H. J. 1954. Nature of genetic effects produced by radiation. In Radiation Biology. A. Hollander, Ed. Vol. 1. part 1. : 351-474. McGraw-Hill Book Co. New York, N. Y. 